\title{
Balance Characteristics and Frequency of Falls in Patients with Postmenopausal Osteoporosis
}

\author{
Mohamad Hanafy, Hesham Hamoud*, Samy Abdulhakim and Hasan Awwad \\ Rheumatology Department, Al Azhar University, Egypt
}

Submission: July 25, 2017; Published: August 04, 2017

*Corresponding author: Hesham Hamoud, Rheumatology Department, Al Azhar University, Cairo, Egypt, Email: hamoud.hesham@yahoo.com

\begin{abstract}
Introduction: People affected by osteoporosis are at particular risk for bone fractures caused by falls. Preventive intervention depends on describing the risk factors that increase the tendency for falls among that population group.

Objectives: To study the balance characteristics in patients with postmenopausal osteoporosis and its relationship to the frequency of falls.

Patients and methods: Fifty postmenopausal females with osteoporosis, diagnosed on the basis of their T-score \& bone mineral density, were included in this study; their ages were ranged from 55-78 years. The patients were divided into two groups:- Group I:- postmenopausal osteoporosis with normal posture $(\mathrm{n}=25)$ and Group II- postmenopausal osteoporosis with kyphosis $(\mathrm{n}=25)$. Kyphosis was defined as a Cobb angle of more than $54^{\circ}$.

Results: Both groups with osteoporosis had a different balance control characteristics. Postmenopausal osteoporosis with spinal Kyphosis had greater postural sway than those without spinal Kyphosis.

Conclusion: Patient with osteoporosis, particularly those with kyphosis have unique balance features with high SI that may destabilize them during activities of daily life. The use of balance stabilometry to assess balance in person with osteoporosis promises to predict the frequency of falls as well as balance rehabilitation may help to reduce falls.
\end{abstract}

\section{Introduction}

Postural instability and impaired balance are increased with age. Loss of balance and increased body sway are important risk factors for falls in the postmenopausal women [1]. The agerelated increased incidence of osteoporotic fractures usually due to the combination between increased fall risk and diminished bone strength. The risk of falls is greater in older persons, with the annual incidence increasing up to $50 \%$ in those over age 80 [2]. Although various factors are associated with falls, impaired balance and mobility have been consistently identified as the main risk factors [3].

In fact, almost $30 \%$ of elder women than 60 years fall at least once a year [4]. Fall prevention should be routine in the management for postmenopausal women [5]. Most falls in the elderly are caused by complex interactions of intrinsic (physiological) and extrinsic (environmental) factors $50 \%$ of falls in the elderly can be attributed to accidents and extrinsic causes such as slippery floors, the remainder from intrinsic causes such as lower extremity weakness, gait disorders. Falls are considered as a significant source of disability and death in elders as well as a serious threat to their psychologic and physical health. Almost $30-50 \%$ of falls result in minor soft tissue injuries that do not require medical attention $10.1 \%$ of falls result in hip fractures; $3-5 \%$ result in other types of fractures, $5 \%$ produce serious soft tissue injuries [6]. In the States, approximately 10,000 deaths each year are related to falls taken by elderly patients; the vast majority of these deaths are related to hip fractures. $25 \%$ of elderly patients who have fallen report that they avoid essential activities such as mobility in the home, bathing and dressing because the fear of falling again [6].

Because of the significant incidence of falls among the elderly, physicians should have an organized approach to fall assessment and prevention. Reduction in fall risk is focused on exercises aiming to improve balance and muscle strength, adjusting medication use and diminishing the danger for falls at home [7]. The aim of this work is to study the balance characteristics in patients with postmenopausal osteoporosis and its relationship to the frequency of falls. 


\section{Orthopedics and Rheumatology Open Access Journal}

\section{Patients \& Methods}

Fifty postmenopausal females with osteoporosis were included in this study, diagnosed according to their T-score $(<-2.5) \&$ bone mineral density (BMD) that measured by a DXA scanner LUNAR Madison, WI prodigy/DPX Series High Voltage Power Supply, model 7681 that manufactured by USA, 2008 (Figure 1). Their ages were ranged from 55-78 years. The patients were divided into two groups:- Group Ipostmenopausal osteoporosis with normal posture $(n=25)$ and Group II- postmenopausal osteoporosis with kyphosis $(n=25)$.

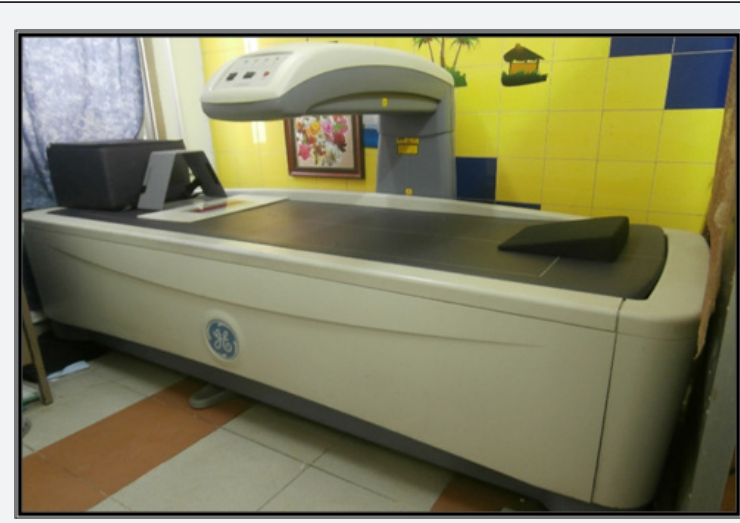

Figure 1: DXA scanner LUNAR Madison, WI prodigy/DPX Series High Voltage Power Supply, model 7681 that manufactured by USA, 2008.

Kyphosis was defined as a Cobb angle of more than $54^{\circ}$. All patients ambulated independently and had not a fall while performing daily activities during the previous one year. Every patient was asked about the unexplained falls during the last year. The following criteria were used to select the study group:-

i. No current or past medical diagnosis or injury affecting balance.

ii. No medications affecting CNS or known to affect balance.

iii. No symptoms suggesting neurological disorders.

iv. No psychological diseases.

v. Normal vision with or without glasses.

Balance stabilometry by biodex stability system (BSS), and Quadriceps strength (maximum isometric contraction) was measured to both groups. Quadriceps strength (maximum isometric contraction) was measured for both groups in the sitting position for the dominant (stronger) leg with a horizontal spring gauge calibrated to $30 \mathrm{~kg}$ force.

\section{Balance Assessment}

All patients completed a both-leg static balance assessment for both limbs on the B S S (Biodex, Shirley, NY). Which is designed to stimulate joint mechano-receptors and to promote reflex muscular activation necessary for joint stability [8]. The dependent measurement obtained from the Biodex Stability System, was the Stability Index (SI), which was calculated online and quantified the subject's ability to control the platform's angle of tilt during a test. A high SI (e.g.,> 5.93) is indicative of a lot of movement during a test and therefore less stability. However, a lower SI (e.g., < 0.66) reflects less time spent away from the level position; a lower SI is therefore interpreted as a better balance score. Both of the studied groups performed the balance test for both lower extremities at two stability levels: more stable "6" and less stable" $2 "$.

These two levels were selected because they represent, respectively, a fairly stable platform surface " 6 " and an unstable platform surface "2". A device-generated SI was recorded under the two tests conditions:-

\section{a. Both limbs at level "6"}

b. Both limbs at level "2", then a mean SI was calculated The object of the dynamic balancing test was to actively move the platform within a specified range by relying on visual feedback from the balance device.

The dynamic balance test required each patient to actively tilt the platform in the single plane directions of:-

i. Anterior and posterior tilt, and

ii. Medial and lateral tilt, while staying within the boundaries defined by the A-circle of the device's visual feedback screen.

Informed consent was obtained from all patients, and the study was approved by the Research Ethics Committee. According to the participants' history, the occurrence and sites of falls in the past 12 months were observed

\section{Results}

(Tables 1-4) (Figure 2).

Table 1: The demographic data, T-score, Stability Index, (AP and ML stability) \& freq. of falls in both Kyphotic and Non-Kyphotic patients: where stability index (specialy AP stability), and the frequencies of falls were significantly higher, however T-score was significantly lower in kyphotic than non-kyphotic group.

\begin{tabular}{|c|c|c|c|}
\hline & Kyphotic & Non Kyphotic & P \\
\hline Age & $68,2 \pm 9.12$ & $67,6 \pm 8,59$ & NS \\
\hline Weight & $63,2 \pm 5.22$ & $61,7 \pm 6.8$ & NS \\
\hline Height & $153.6 \pm 3.62$ & $161,6 \pm 9.51$ & $<0.05$ \\
\hline T-score & $-3.37 \pm .95$ & $-2.33 \pm 1$ & $<0.01$ \\
\hline Stability.Index & $10.39 \pm 1.1$ & $6.82 \pm 0.9$ & $<0.01$ \\
\hline AP. Stability & $7.70 \pm 2.15$ & $4.36 \pm 1.30$ & $<0.01$ \\
\hline ML.Stability & $5.83 \pm 1.22$ & $3.37 \pm 1.88$ & $<0.05$ \\
\hline Fall Frequencies & 6.0 & 4.0 & $<0.01$ \\
\hline
\end{tabular}


Table 2: Correlation between Stability index and demographic data of Kyphotic Patients.

\begin{tabular}{|c|c|c|c|c|}
\hline & Age & Height & Weight & T-Score \\
\hline Stability index & 0.65 & 0.32 & -0.66 & -0.62 \\
\hline AP- Stability & -0.74 & -0.39 & 0.75 & 0.89 \\
\hline ML- Stability & 0.65 & -0.32 & 0.72 & 0.67 \\
\hline
\end{tabular}

Table 3: Correlation between stability and demographic data of Non Kyphotic Patients Where there is a direct negative correlation between T-Score and stability index among both of the kyphotic \& non-kyphotic groups.

\begin{tabular}{|c|c|c|c|c|}
\hline & Age & Weight & Height & T-Score \\
\hline Stability index & 0.372 & 0.157 & -0.668 & -1.10 \\
\hline AP-Stability & -0.011 & -0.241 & -0.380 & -0.423 \\
\hline ML- Stability & $0.526-$ & -0.181 & 0.364 & -0.337 \\
\hline
\end{tabular}

Table 4: Correlations between Stability index and fall-down among kyphotics \& non-kyphotics where T-Score and stability index showed an inverse relationship with the frequency of falls among the Kyphotic group.

\begin{tabular}{|c|c|c|c|c|}
\hline \multirow{2}{*}{} & \multicolumn{2}{|c|}{ T-Score } & \multicolumn{2}{c|}{ Stability Index } \\
\cline { 2 - 5 } & Kyphotic & $\begin{array}{c}\text { Non. } \\
\text { Kyphotic }\end{array}$ & Kyphotic & $\begin{array}{c}\text { Non. } \\
\text { Kyphotic }\end{array}$ \\
\hline \multirow{2}{*}{ Fall-down } & 0.72 & 0.38 & 0.72 & 0.44 \\
\cline { 2 - 5 } & $*$ & NS & $*$ & NS \\
\hline
\end{tabular}

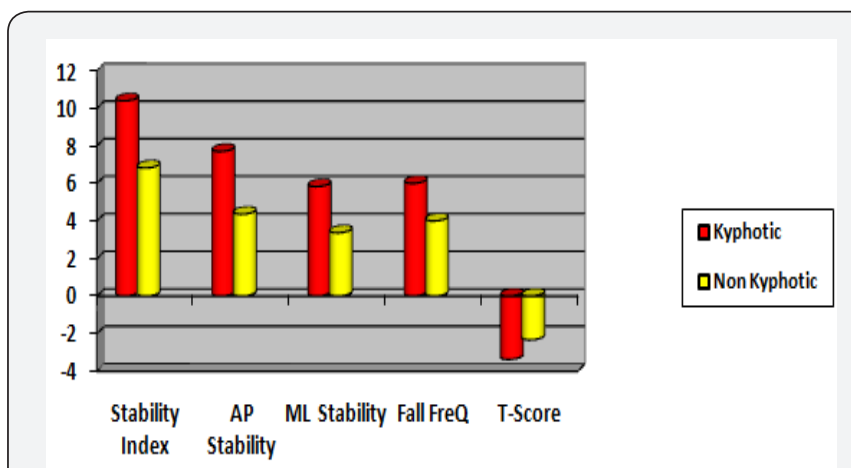

Figure 2: T-score, Stability Indices \& frequency of falls in both Kyphotic and Non-Kyphotic patients.

\section{Discussion}

Falls in elderly are a very costy problem, in both financial and quality of life terms. Falls are not normal and may be largely preventable. For many years, it was not possible to predict the tendency to fall, but it is possible to identify individual risk factors which contribute to falls [9]. The relationship between bone loss and fracture was probably first made by Antley Cooper in 18241, when he suggested that the increased frequency of falls \& fracture was due to thinning of bone in elderly peoples. Bone fractures resulting from falls are most likely to occur in aging women. In their observations of residents of Rochester, Minnesota, in 1985, Melton \& Riggs [10] had been noted that the rate of falls-related fractures was inversely related to bone density. In consistence with Melton and Riggs's study, we observed that the stability index, AP stability \& ML stability were inversely correlated with T-score and directly correlated with both age \& frequency of falls in both kyphotic \& non kyphotic groups.

The present study demonstrated quadriceps muscle weakness more in kyphotics than non-kyphotics, consistent with Wolfson et al. [11] who stated that, the decreased balance functioning in elderly subjects (high stability index) is probably related to loss of strength in the lower extremities, suggesting that quadriceps muscle strength may play an important role as a risk of falls and its strength has a very important therapeutic implications [12]. As a conventional model for fracture prediction, the hypothesis that osteoporotic fracture is a direct consequence of low bone mineral density and poor postural stability and hence falls [13].

Cummings et al. suggested synergism between the predictor variables (BMD, postural stability \& lower limb muscle strength) and may indicate that treatment to improve even one predictor variable (for example, bone density) could reduce the fracture risk substantially [14]. Our data suggest that postural stability may be one such major factor, as postural instability (SI) tends to worsen with age as agreed with that reported by Hui et al. [15] who identified age and bone mass as significant independent predictors, and considered age as a surrogate for other age related factors.

Horak and colleagues observed an increased dependency on a hip strategy occur with age. A hip strategy is normally used when a quick postural adjustment is required or when standing on a small support surface. An ankle strategy is more likely used when standing on a large, flat surface, and it entails a slower adjustment of the center of gravity than does the hip strategy [11]. In the present study the kyphotic patients had more AP postural sway (low AP stability) leading to greater use of hip strategies than ankle strategies to maintain balance. We speculate that their increased reliance on hip strategies may have resulted from the flexed posture, shifting the body's center of gravity closer to the limits of stability.

Data in the literature indicate a frequency of falls from $30 \%$ to $60 \%$ for the evaluated patients $[4,5,16]$ and that women are more likely to have a fall when compared men [17]. Osteoporosis is responsible for body configuration changes that can interfere with postural control $[16,18]$. On the other hand, Silva et al. [13] reported that the risk for falls in 133 women with osteoporosis, aged 60 years or greater, was 2 folds higher as compared to that in 133 women with normal bone mass [16]. It is known that osteoporosis can lead to spinal deformities such as thoracic kyphosis due to vertebral compression that alters the structure of the spine, causing weakness of the extensor muscles of the trunk and leading to reduced physical mobility and flexibility. In severe kyphotic posture, the body moves forward leading to a shifting the center of balance, coming close to stability limits $[4,16]$. Our study showed greater changes instability indices 
among the kyphotic compared to the non kyphotic group [1921]. Previous studies showed similar results to our results $[4,5]$. Piirtola \& Era performed a systematic review regarding use of the force platform as a fall indicator in older patients [22-24]. Age is an important factor that contributes to postural control changes. In most studies on falls in older individuals, good performance was maintained until the age of 45-55 years, depending on the effort demanded. After such age range, a gradual deterioration in performance was observed [24-28].

\section{Conclusion}

Patient with postmenopausal osteoporosis, and in particularly those with kyphosis have unique balance features with high stability index that may destabilize them during the activities of daily life. The use of balance stabilometry to assess the balance characteristics in patients with postmenopausal osteoporosis is promising to predict the frequency of falls. Balance rehabilitation may help to reduce falls. In the meantime, it seems logical to objectively assess the balance characteristics in patients with postmenopausal osteoporosis who are at risk for injurious falls as a means to provide the best rehabilitation programs available that may help to reduce falls.

\section{Clinical Implications}

Major predictors of incidence of falls included bone density, impaired postural stability \& lower limb muscle strength; these predictors were synergistic, so that a person with all these predictors will be in the highest risk of falls and fracture. Interactions between risk factors must be investigated in a large population based community study.

\section{References}

1. Arnold CM, Busch AJ, Schachter CL, Harrison L, Olszynski W (2005) The relationship of intrinsic fall risk factors to a recent history of falling in older women with osteoporosis. J Orthop Sports Phys Ther 35(7): 452-460.

2. Horak FB, Shupert CL, Mirka A (1989) Components of postural dyscontrol in the elderly: a review. Neurobiol Aging 10(6): 727-738.

3. Barrett-Cornor E, Weiss TW, McHorney CA, Miller PD, Siris ES (2009) Predictors of falls among postmenopausal women: results from the National Osteoporosis Risk Assessment (NORA). Osteoporos Int 20(5): 715-722.

4. Tinetti ME, Speechley M, Ginter SF (1988) Risk factors for falls among elderly persons living in the community. N Engl J Med 319(26): 17011707.

5. Gillespie LD, Gillespie WJ, Robertson MC, Lamb SE, Cumming RG, et al. (2003) Interventions for preventing fall in elderly people. Cochrane Database Syst Rev 4: CD000340.

6. Brunt D (2005) Plantar feedback contributes to the regulation of leg stiffness. Clinical Biomechanics 20(9): 952-958.

7. Blake AJ, Morgan K, Bendall MJ, Dallosso H, Ebrahim SB, et al. (1988) Falls by elderly people at home: prevalence and associated factors. Age Ageing 17(6): 365-372.

8. Sinaki M, Brey RH, Hughes CA, Larson DR, Kaufman KR (2005) Balance disorder and increased risk of falls in osteoporosis and kyphosis: significance of kyphotic posture and muscle strength. Osteoporos Int 16(8): 1004-1010.
9. Allison l (1997) Risk factors for fall. New England Journal of Medicine 321: 821-827.

10. Melton LJ III, Riggs BL (1985) Risk factors for injury after a fall. Clin Geriatr Med 1: 525-539.

11. Wolfson L, Whipple R, DerbyCA, Amerman P, Murphy T, et al. (1992) A dynamic posturography study of balance in healthy elderly. Neurology 42(11): 2069-2075.

12. Cummings SR, Black DM, Nevitt MC, Browner W, Cauley J, et al. (1993) Bone density at various sites for prediction of hip fractures. Lancet 341(8837): 72-75.

13. Silva RB, Costa-Paiva L, Oshima MM, Morais SS, Pinto-Neto AM (2009) Frequency of fall and association with stabilometry parameters of balance in postmenopausal women with and without osteoporosis. Rev Bras Ginecol Obstet 31(10): 496-502.

14. Melton LJ III, Kan SH, Frye MA, Wahner HW, O’Fallon WM, et al. (1989) Epidemiology of vertebral fractures in women. AM J Epidemiol 129(5): 1000-1011.

15. Hui SL, Slemenda CW, Johnton CC (1988) Age and bone mass as predictors of fracture in prospective studies. J Clin Invest 81: 18041809.

16. Painter JA, Elliott SJ, Hudson S (2009) Falls in community-dwelling adults aged 50 years and older: prevalence and contributing factors. J Allied Health 38(4): 201-207.

17. Abreu DCC, Trevisan DC, Reis JG, Gustavo de Carvalho da Costa, Matheus Machado Gomes, et al. (2009) Body balance evaluation in osteoporotic elderly women. Arch Osteoporos 4: 25-29.

18. Gunend Z, Demirsoy N (2007) Clinical and Computerized Stabilometrical Evaluation of Postural Balance in Postmenopausal Women with Osteoporosis. Turk J Phys Med Rehab 53(1): 130-133.

19. Keskin D, Borman P, Ersöz M, Kurtaram A, Bodur H, et al. (2008) The risk factors related to falling in elderly females. Geriatr Nurs 29(1): 5863.

20. Piirtola M, Era P (2006) Force platform measurements as predictors of falls among older people: a review. Gerontol 52(1): 1-16.

21. Haber NEL, Erbas B, Hill KD, Waek JD (2008) Relationship between age and measures of balance, strength and gait: linear and non-linear analyses. Clin Sci 114(12): 719-727.

22. Antley Cooper A (1824) Treatise on dislocation and fractures of the joints. ( $4^{\text {th }}$ edn), Longman, London, UK.

23. Cooper C, Aitkinson EJ, O’Fallon WM, Melton LJ (1992) Incidence of clinically diagnosed vertebral fractures: a population based study in Rochester, Minnesota, 1985-1989. J Bone Miner Res 7: 221-227.

24. Cooper C, Aitkinson EJ, O'Fallon WM, Melton LJ (1992) Incidence of clinically diagnosed vertebral fractures: a population based study in Rochester, Minnesota, 1985-1989. J Bone Miner Res 7: 221-227.

25. Nevitt MC, Cummings SR, Hudes ES (1991) Risk factors for injurious falls: a prospective study. J Gerontol 46(5): M164-170.

26. Tinetti ME, Speechley M, Ginter SF (1990) Risk factors for falls among elderly persons living in the community. N Engl J Med 319(26): 17011707.

27. Horak FB, Jones-Rycewicz C, Black FO, Shunway-Cook A (1992) Effects of vestibular rehabilitation on dizziness and imbalance. Otolaryngol Head Nec surg 106(2): 175-80.

28. Sattin RW (1992) Falls Among Older Persons: A Public Health Perspective Annu Rev Public Health 13: 489-508. 
This work is licensed under Creative Commons Attribution 4.0 License DOI: $10.19080 /$ ROAJ.2017.08.555730
Your next submission with Juniper Publishers will reach you the below assets

- Quality Editorial service

- Swift Peer Review

- Reprints availability

- E-prints Service

- Manuscript Podcast for convenient understanding

- Global attainment for your research

- Manuscript accessibility in different formats

( Pdf, E-pub, Full Text, Audio)

- Unceasing customer service

Track the below URL for one-step submission https://juniperpublishers.com/online-submission.php 